\title{
Cyclosporin treatment of IgA nephropathy: a short term controlled trial
}

\author{
KAR NENG LAI, FERNAND MAC-MOUNE LAI, PHILIP K T LI, \\ JOHN VALLANCE-OWEN
}

\begin{abstract}
Cyclosporin's known regulatory effects on the immune system suggest that it may be useful in treating patients with IgA nephropathy. A randomised prospective single blind study of 19 patients with IgA nephropathy and proteinuria ( $>1.5 \mathrm{~g} /$ day) was conducted to determine the therapeutic value of cyclosporin. The patients were divided into two groups: nine patients were given oral cyclosporin $(5 \mathrm{mg} / \mathrm{kg} / \mathrm{day})$ for 12 weeks and 10 patients a placebo. The two groups were comparable in age of presentation, ratio of men to women, plasma creatinine and serum IgA concentrations, creatinine clearance, daily urinary protein excretion, severity of renal histopathological changes, and prevalence of hypertension. A significant reduction of proteinuria and an increase of plasma albumin concentration was observed with treatment with cyclosporin. Nevertheless, a significant rise of plasma creatinine concentration and a fall in creatinine clearance was found in patients after six weeks' treatment with cyclosporin, although the plasma cyclosporin concentrations were maintained within a narrow therapeutic range. Serum IgA concentrations were reduced in seven patients. Renal function improved within eight weeks after treatment was stopped. Three months after treatment was stopped proteinuria remained less than half of the pretreatment values in three patients. No similar biochemical changes were observed in the controls.

Short term cyclosporin therapy may be beneficial in reducing proteinuria in some patients with IgA nephropathy. As transient renal impairment was seen, despite cyclosporin concentrations
\end{abstract}

\footnotetext{
Departments of Medicine and Morbid Anatomy, Prince of Wales Hospital, Chinese University of Hong Kong, Shatin, New Territories, Hong Kong

KAR NENG LAI, MD, MRCP, senior lecturer in medicine FERNAND MAC-MOUNE LAI, MD, lecturer in morbid anatomy PHILIP K T LI, MB, MRCP, registrar, medical unit JOHN VALLANCE-OWEN, MD, FRCP, professor of medicine

Correspondence to: Dr K N Lai.
}

being maintained within a narrow therapeutic range, indiscriminate use of cyclosporin in glomerulonephritis should be discouraged.

\section{Introduction}

Initial reports suggested that primary IgA nephropathy had a benign course, but progression to end stage renal failure has subsequently been observed in $8 \%$ to $33 \%$ of cases. ${ }^{12}$ Treatment was reported to be uniformly ineffective. ${ }^{3}$ Trials with phenytoin, which can reduce serum titres of $\operatorname{IgA}$, failed to show any important effect of this drug on the clinical progress or histopathology of the disease. $^{34}$ Similarly, our recent randomised controlled trial failed to show any benefit of corticosteroids in patients with IgA nephropathy, apart from a selected group of patients with minor glomerular lesions and the nephrotic syndrome.

Cyclosporin is a fungal peptide with unique immunoregulatory properties, inhibiting activation of both $B$ and $T$ lymphocytes and certain functions of macrophages. ${ }^{6}$ Isolated case reports have shown stabilisation of renal functions in patients with $\operatorname{IgA}$ nephropathy treated with cyclosporin. ${ }^{7}$ Cyclosporin has also been shown to block the development of glomerulonephritis induced experimentally in mice by antibodies. ${ }^{89}$ Thus it may have some therapeutic effect on glomerular lesions induced immunologically in IgA nephropathy. We report our randomised prospective single blind trial of treatment with cyclosporin in 19 patients with IgA nephropathy.

\section{Patients and methods \\ SELECTION OF PATIENTS}

Patients selected for this study had an immunopathological diagnosis of IgA nephropathy. They had had symptoms for 12 months or more, had proteinuria of at least $1.5 \mathrm{~g} /$ day, and were aged 16 to 60 years. IgA nephropathy was diagnosed on ultrastructural examination from the presence of predominant IgA deposits mainly in the mesangium and mesangial and paramesangial electron dense deposits. ${ }^{10}$ Systemic lupus erythematosus, Henoch-Schönlein purpura, and hepatic disease were excluded by detailed clinical history, examination, and negative results 
from laboratory tests for hypocomplementaemia, antideoxyribonucleic acid antibody, or hepatitis B surface antigen. Exclusion criteria were: endogenous creatinine clearance of less than $50 \mathrm{ml} / \mathrm{min} / 1 \cdot 73 \mathrm{~m}^{2}$; previous treatment with cytostatic agents such as antilymphocyte globulin; corticosteroid treatment within four weeks before the study; thromboembolic diseases; active infection; malignancy; uncontrolled hypertension; impaired liver function; history of epilepsy; and concomitant treatment with nephrotoxic drugs. Patients eligible for this trial received detailed information about the trial and the potential risks of cyclosporin treatment, and we required their written informed consent.

\section{HISTOPATHOLOGICAL GRADING}

Biopsy specimens were examined under a light microscope to evaluate glomerular changes, which were classified into grades 1-3 according to severity. ${ }^{10}$ Grade 1 denoted the mild mesangial proliferation (cells, matrix, or both) with or without mild tubulointerstitial changes; grade 2 indicated a moderate degree of mesangial proliferation and an increase in matrix, occasionally with glomerulosclerosis and crescent formation (in less than $20 \%$ of the glomeruli), and a moderate degree of tubulointerstitial change; grade 3 denoted the presence of findings as for grade 2 but with more than $30 \%$ glomerulosclerosis, more crescent formation, and more advanced tubulointerstitial changes.

\section{TREATMENT}

All the patients with hypertension were treated with nadolol to maintain their blood pressures below $150 / 90 \mathrm{~mm} \mathrm{Hg}$. All patients were given a number in the trial based on their order of entry into the study, which determined their allocation to the treatment or placebo group; allocation was randomised by a computer, which generated a list given to us by the immunology department of Sandoz Pharmaceuticals. After having been selected patients entered a run in phase for two weeks with a complete biochemical investigation at the beginning and the end. All treatments, except that for hypertension, were stopped at entry to the run in phase.

Cyclosporin and the placebo preparation looked identical and were given orally in two equal doses daily. The initial dosage of cyclosporin was $5 \mathrm{mg} / \mathrm{kg} /$ day and that of the placebo $0.05 \mathrm{ml} / \mathrm{kg} /$ day. We decided to reduce the dose of cyclosporin by $20 \%$ if plasma creatinine concentration exceeded $25 \%$ of the baseline value or the plasma cyclosporin trough concentration (concentration measured 12 hours after administration) reached $150 \mu \mathrm{g} / \mathrm{l}$ (evaluated by radioimmunoassay with a Sandoz kit). Similarly we decided to increase the dose of cyclosporin by $20 \%$ if the plasma cyclosporin trough concentration fell below $45 \mu \mathrm{g} / \mathrm{l}$. The treatment was given for 12 weeks. After that the dose of cyclosporin was reduced by increments of $25 \%$ every four days over two weeks to avoid a rebound effect. We adopted a similar regimen for reducing the amount of placebo.

Visits to outpatient clinics were scheduled at weeks $1,2,4,6,9$, and 12 and then monthly for three months. Blood cell counts, renal and liver function tests, endogenous creatinine clearance, proteinuria over 24 hours, and plasma cyclosporin trough concentrations were measured during these visits. Serum IgA and complement concentrations were measured before, during, and after the trial. The patients were interviewed by telephone weekly about any side effects.

\section{CLINICAL AND LABORATORY EVALUATION}

A reduction in urinary protein excretion to less than $0.5 \mathrm{~g} /$ day was defined as complete remission of proteinuria, and proteinuria reduced to at least half of the mean of the two run in, baseline measurements was defined as partial remission. Patients were withdrawn from the treatment with cyclosporin if the following conditions occurred: potentially lifethreatening infection; persistently raised values on liver or renal function tests despite two reductions in dose; pregnancy; uncontrolled hypertension; or important side effects that were not corrected by a reduction in dose.

\section{STATISTICS}

The results were expressed as means (standard error of the mean). The rank sum (two population) or Wilcoxon's sign rank test was used to analyse differences in plasma creatinine concentrations, creatinine clearance, urinary protein excretion, serum IgA concentrations, age, and duration of illness between the two groups. Fisher's exact test was used to analyse differences in the incidence of clinical presentation and histopathological changes between the two groups.

\section{Results}

\section{CLINICAL AND PATHOLOGICAL FINDINGS}

The study comprised 10 men and nine women (aged 24-58, mean 26 years). Nine patients received treatment with cyclosporin and 10 the placebo. Table I summarises the clinical features of the two groups. The ratio of men to women, age at presentation, and prevalence of hypertension were not significantly different between the two groups. Moderate ankle oedema was seen in two patients in the treatment group and one in the control group.

TABLE I-Clinical features of the 19 patients in trial. Values are means (SEM)

\begin{tabular}{|c|c|c|}
\hline & \multicolumn{2}{|c|}{ Treatment group } \\
\hline & $\begin{array}{c}\text { Cyclosporin } \\
(n=9)\end{array}$ & $\begin{array}{l}\text { Placebo } \\
(n=10)\end{array}$ \\
\hline $\begin{array}{l}\text { Ratio of men: women } \\
\text { Mean age (years) } \\
\text { Mean time of follow up after renal biopsy (months) }\end{array}$ & $\begin{array}{l}4: 5 \\
33 \cdot 1(1 \cdot 4) \\
15 \cdot 7(3 \cdot 9)\end{array}$ & $\begin{array}{l}6: 4 \\
38 \cdot 7(4 \cdot 1) \\
14 \cdot 5(3 \cdot 5)\end{array}$ \\
\hline $\begin{array}{l}\text { Renal manifestation at biopsy: } \\
\text { Macroscopic haematuria } \\
\text { Asymptomatic proteinuria } \\
\text { Microscopic haematuria } \\
\text { Proteinuria and microhaematuria } \\
\text { Nephrotic syndrome }\end{array}$ & $\begin{array}{l}1 \\
3 \\
2 \\
3\end{array}$ & $\begin{array}{l}2 \\
3 \\
1 \\
4\end{array}$ \\
\hline Hypertension & 2 & 2 \\
\hline $\begin{array}{l}\text { Biochemical results at start of study: } \\
\text { Plasma creatinine }(\mu \mathrm{mol} / \mathrm{l}) \\
\text { Plasma albumin }(g / 1) \\
\text { Creatinine clearance }\left(\mathrm{ml} / \mathrm{min} / 1 \cdot 73 \mathrm{~m}^{2}\right) \\
\text { Urinary protein }(g / \text { day }) \\
\text { Serum IgA }(\mathrm{g} / \mathrm{l})\end{array}$ & $\begin{array}{c}111.6(14 \cdot 6) \\
36.4(2 \cdot 3) \\
73 \cdot 1(6.5) \\
4 \cdot 2(1 \cdot 1) \\
3.9(0.4)\end{array}$ & $\begin{array}{c}119.1(10.2) \\
39.8(3.3) \\
71.7(3.3) \\
2.5(0.3) \\
2.9(0.3)\end{array}$ \\
\hline
\end{tabular}

Plasma albumin concentration, plasma creatinine concentration, and creatinine clearance during the run in phase were similar for both groups. The mean 24 hour urinary protein excretion and serum IgA concentrations for patients receiving cyclosporin were higher than the values for patients in the control group receiving placebo, but not significantly so. Statistical analysis showed no significant difference in the severity of renal histopathological changes between the two groups (table II).

TABLE II-Comparison of severity of renal histopathological changes between patients receiving cyclosporin and those receiving placebo. Values are numbers of patients

\begin{tabular}{lcccc}
\hline & \multicolumn{3}{c}{ Renal histopathological changes } \\
\cline { 2 - 5 } & Grade 1 & Grade 2 & Grade 3 \\
\hline Cyclosporin group & 6 & 3 & 0 \\
Placebo group & 5 & 5 & 0 \\
\hline
\end{tabular}

Fisher's exact test: $p=0 \cdot 394$.

\section{CLINICAL PROGRESS}

All patients completed the trial and the three months of follow up. Figure 1 shows the biochemical results for the two groups. In seven of the nine patients receiving cyclosporin proteinuria fell to less than half of the baseline measurements as early as the second week. The urinary excretion of protein was significantly lower than baseline values during the 12 weeks of treatment, and it increased immediately after treatment with cyclosporin was stopped. Proteinuria remained less than half of baseline values in three patients three months after treatment was stopped. For all patients the mean urinary protein excretion during the three months after completion of the trial was lower than the baseline values, but the difference failed to reach statistical significance. Plasma albumin concentration increased significantly after four weeks of cyclosporin treatment but fell one month after treatment was stopped. Ankle oedema in the two patients in the cyclosporin group disappeared quickly with treatment.

Despite the satisfactory changes in plasma albumin and urinary protein concentrations we noted an overall deterioration of renal function during treatment with cyclosporin. Plasma creatinine concentration rose progressively from the second week of treatment, and creatinine clearance was 
significantly impaired six and nine weeks after treatment with cyclosporin was started. Renal impairment was likely to be associated with the nephrotoxic effect of cyclosporin as no patient experienced a hypotensive episode or was given any other nephrotoxic agents during the 12 weeks of the trial. Table III shows the mean maintenance doses of cyclosporin and the plasma cyclosporin trough concentrations during the trial. We maintained
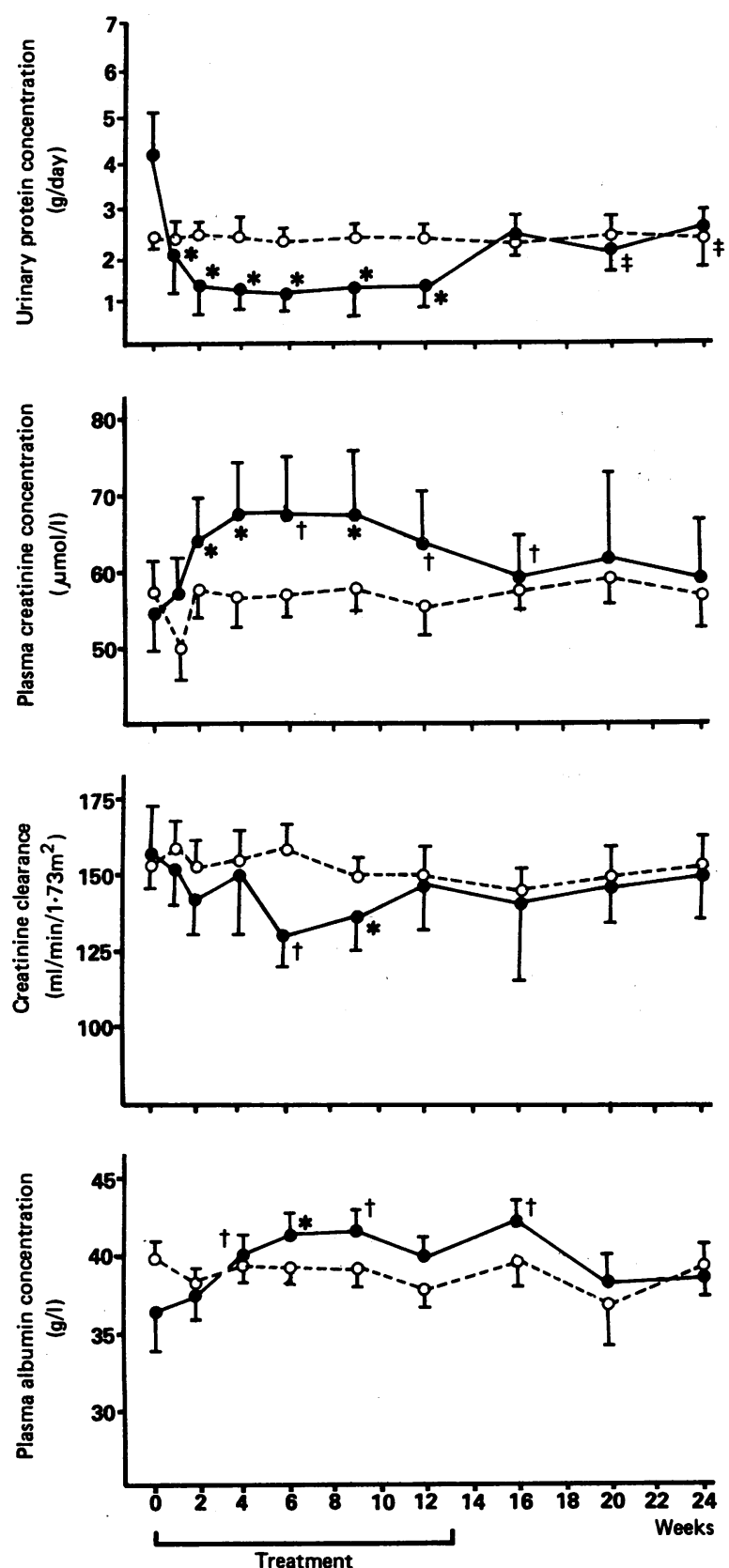

FIG 1 -Changes in urinary protein concentration, plasma creatinine concentration, creatinine clearance, and plasma albumin concentration in patients receiving either cyclosporin $(\bullet-\bullet)$ or placebo $(0--0)$. Values are means (SEM); ${ }^{\star} \mathrm{p}<0.01, \mathrm{tp}<0.02, \neq \mathrm{p}<0.05$ when compared with mean value before treatment.

TABLE III-Dose of cyclosporin and plasma cyclosporin trough concentrations in nine patients receiving treatment with cyclosporin. Values are means (SEM)

\begin{tabular}{lcc}
\hline $\begin{array}{c}\text { Weeks of } \\
\text { treatment }\end{array}$ & $\begin{array}{c}\text { Dose of cyclosporin } \\
(\mathrm{mg} / \mathrm{kg} / \text { day })\end{array}$ & $\begin{array}{c}\text { Plasma cyclosporin } \\
\text { trough concentration } \\
(\mu \mathrm{g} / \mathrm{l})\end{array}$ \\
\hline 2 & $4 \cdot 9(0 \cdot 1)$ & $80 \cdot 6(22 \cdot 3)$ \\
4 & $4 \cdot 7(0 \cdot 3)$ & $105 \cdot 8(38 \cdot 4)$ \\
6 & $4 \cdot 3(0 \cdot 4)$ & $62 \cdot 7(6 \cdot 7)$ \\
12 & $4 \cdot 4(0 \cdot 5)$ & $68 \cdot 1(7 \cdot 6)$ \\
\hline
\end{tabular}

a narrow therapeutic range of plasma cyclosporin concentration of $55-100 \mu \mathrm{g} / 1$ by careful adjustments of the dose. The nephrotoxic effect of cyclosporin was not apparently related to dose, thus suggesting that these patients had an enhanced sensitivity to cyclosporin nephrotoxicity. Renal impairment was transient: plasma creatinine concentrations and creatinine clearance measured two months after treatment had been stopped were not different from the baseline values.

Serum IgA concentrations fell in seven of the nine patients treated with cyclosporin, but this reduction just failed to reach statistical significance $(p=0 \cdot 1)$ (fig 2). We found variations in clinical and biochemical responses to treatment with cyclosporin among patients (fig 3). One patient, as reported in our separate study, ${ }^{11}$ had steroid dependent nephrotic syndrome due to IgA nephropathy. Clinical remission of the nephrotic syndrome with stable renal function was maintained even though cyclosporin had been stopped for three months. Another patient developed sudden deterioration of renal function and the dose of cyclosporin was reduced by $60 \%$ during the eighth week of treatment. Plasma creatinine concentration and creatinine clearance failed to return to pretreatment values four months after cyclosporin had been stopped.

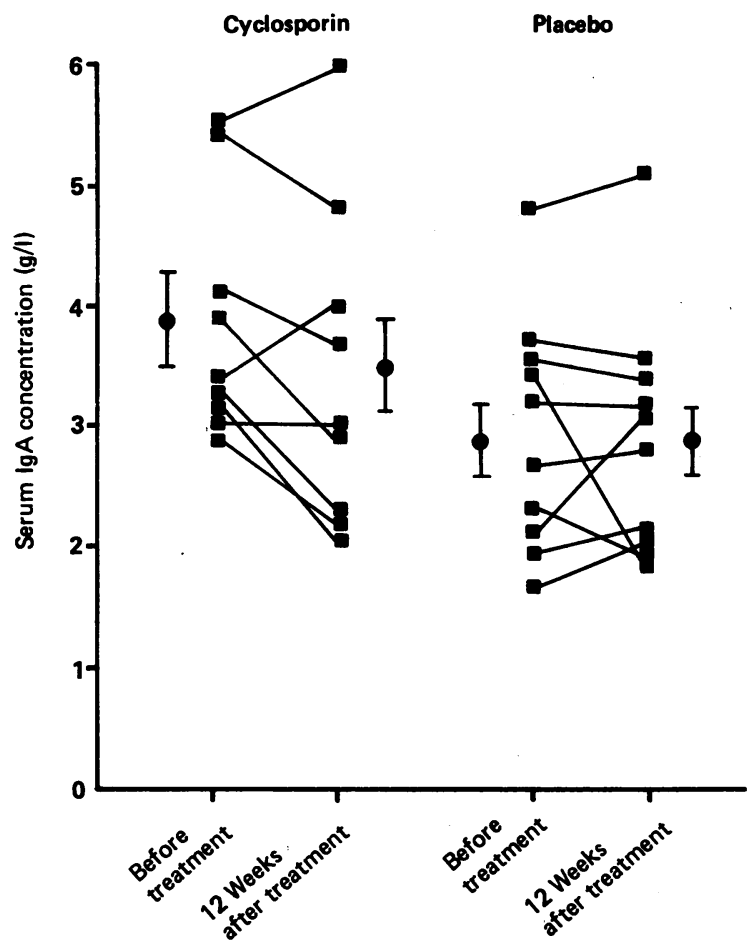

FIG 2-Changes in serum IgA concentrations in patients treated with cyclosporin and placebo. The bars show mean values (SEM).

We found no significant changes in blood counts, urinary sodium excretion, plasma concentrations of electrolytes, or complement concentrations with cyclosporin treatments. Plasma urate concentration was significantly raised with cyclosporin treatment (before treatment 0.44 (SEM $0.07) \mathrm{mmol} / \mathrm{l}$; four weeks $0.52(0.09) \mathrm{mmol} / \mathrm{l}, \mathrm{p}<0.01 ; 12$ weeks 0.52 $(0.09) \mathrm{mmol} / \mathrm{l}, \mathrm{p}<0.001)$. The side effects of treatment were generally unimportant and well tolerated. Hirsutism and epigastric discomfort were the commonest symptoms and transient hyperbilirubinaemia occurred in two patients. Three patients with normal blood pressures developed mild hypertension.

In the 10 patients receiving placebo and acting as controls plasma albumin concentration, plasma creatinine concentration, creatinine clearance, urinary loss of protein, and serum IgA concentrations were unchanged over the 24 weeks of the study.

\section{Discussion}

Increasing data have indicated that IgA nephropathy is an immune complex glomerulonephritis: defective immunoregulation of $T$ helper and $T$ suppressor lymphocytes and hyperactivity of $B$ cells have been shown in this disease. ${ }^{12} 13$ Cyclosporin inhibits 
activation of $\mathrm{T}$ lymphocytes ${ }^{6}$ and can block autoimmune glomerulonephritis in mices ${ }^{8}$; clinically it has been shown to stabilise renal function in IgA nephropathy ${ }^{7}$ and cause remission of the nephrotic syndrome caused by lipoid nephrosis or focal segmental glomerulosclerosis. ${ }^{14}$ These data suggest that a trial of treatment with cyclosporin for glomerulopathy induced immunologically, such as IgA nephropathy, would yield promising results. As the clinical course of IgA nephropathy is so variable, however, the prediction of the outcome for individual or small groups of patients is extremely
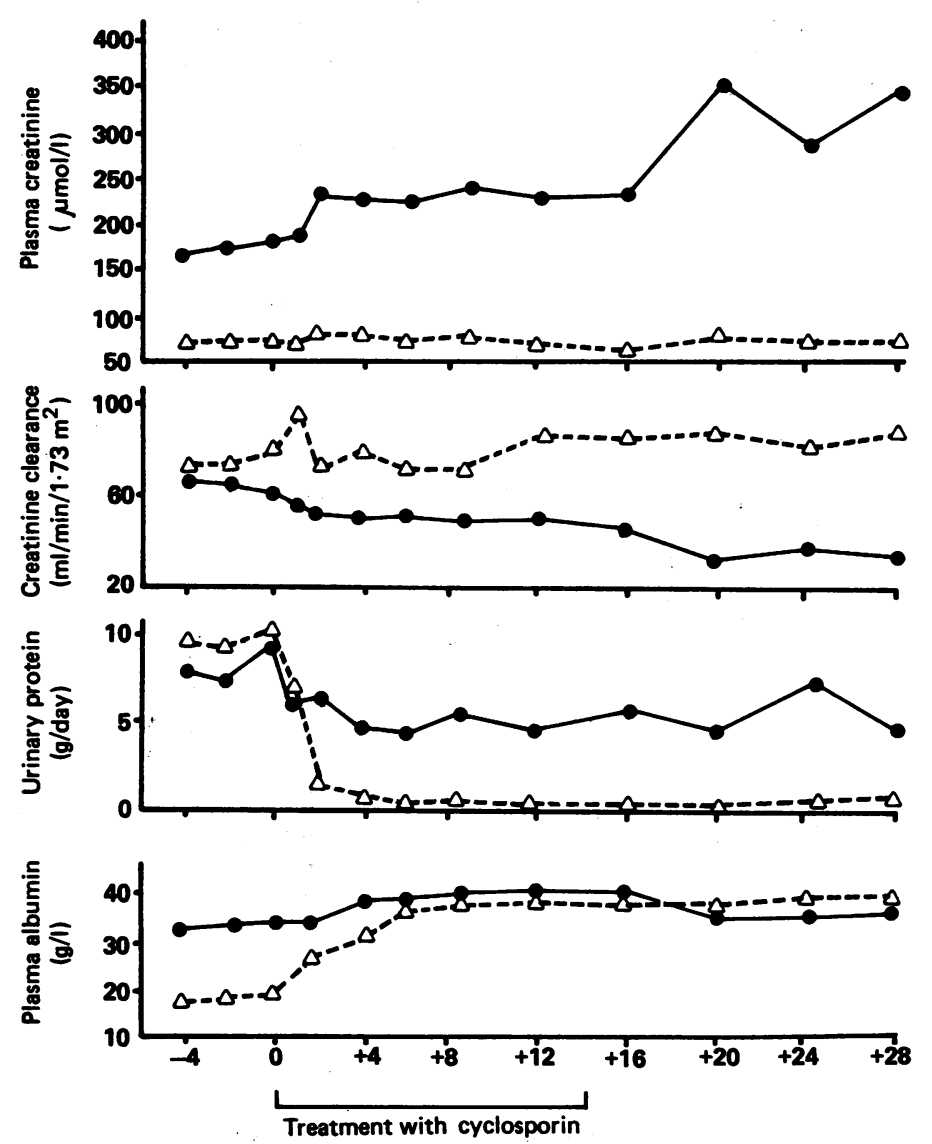

FIG 3-Variation of responses to treatment with cyclosporin in two patients. While full remission of nephrotic syndrome was observed in one patient $(\Delta-\cdot \Delta)$, the other showed mild reduction of proteinuria yet developed significant renal deterioration $(\bullet-\bullet)$.

difficult. An accurate preliminary assessment of treatment with cyclosporin would therefore require controlled studies using treatment and placebo groups.

We studied 19 patients with IgA nephropathy and moderate proteinuria in this placebo controlled, single blind trial to determine the therapeutic value of cyclosporin. The two groups of patients were similar in sex ratio, age of presentation, length of time studied, and renal histopathological changes. Their biochemical findings were comparable. Our results show that cyclosporin significantly reduced proteinuria and increased plasma albumin concentration. These changes were observed as early as the second week of treatment. As reported in patients with the nephrotic syndrome with lipoid nephrosis and focal segmental glomerulosclerosis, ${ }^{14}$ proteinuria reappeared or increased when treatment with cyclosporin was stopped. The effect of cyclosporin on proteinuria may be to modify glomerular anionic changes ${ }^{14}$ or regulate $T$ cell function by blocking the release of a lymphokine. ${ }^{\circ}$ Similarly, the reduction of proteinuria might occur because of a large fall in glomerular filtration rate, ${ }^{5}$ but this was unlikely in our patients as the reduction of glomerular filtration rate with cyclosporin treatment was relatively small. Seven patients $(78 \%)$ showed a reduction of serum
IgA concentrations with cyclosporin treatment, although the numbers were too small to reach statistical significance.

The potential risk of nephrotoxicity associated with cyclosporin deserved careful attention in our analysis. Meyrier $e t$ al reported improved renal function during treatment of idiopathic nephrotic syndrome with cyclosporin. ${ }^{14}$ Cattran et al concluded from their pilot study that cyclosporin could be used for short periods in patients with glomerulonephritis without causing nephrotoxicity.? Renal impairment was reported, however, when cyclosporin was used at treatment for non-renal diseases even though cyclosporin concentrations in the blood were maintained within the therapeutic range. ${ }^{15} 16 \mathrm{We}$ found a significant rise in plasma creatinine concentration and a fall in creatinine clearance after six weeks of treatment, although cyclosporin was given at a comparatively low dose $(4.5-5.0 \mathrm{mg} / \mathrm{kg} /$ day) and the plasma cyclosporin trough concentration was maintained within a narrow therapeutic range. These findings suggest that patients with IgA nephropathy could be extremely sensitive to the nephrotoxic effect of cyclosporin, although the renal impairment is usually reversible when treatment is stopped.

We found variation in the clinical and biochemical responses to cyclosporin among our patients with IgA nephropathy. Although one patient showed irreversible renal impairment even when the dose of cyclosporin was reduced and treatment was subsequently stopped, another showed good remission of her steroid dependent nephrotic syndrome three months after treatment was stopped. As cyclosporin proved to be more effective than placebo in reducing proteinuria in IgA nephropathy a short clinical trial should be considered in those patients with symptoms arising from hypoalbuminaemia and heavy proteinuria. The daily dose should not exceed $5 \mathrm{mg} / \mathrm{kg} / \mathrm{day}$, and renal function and plasma cyclosporin trough concentration should be carefully monitored. Long term continuous cyclosporin treatment of IgA nephropathy should be discouraged and the clinical use of cyclosporin in other forms of glomerulonephritis requires cautious evaluation.

This study was supported by a grant from the Croucher Foundation. We thank Dr B von Graffenreid, immunology department, Sandoz Pharmaceuticals, Basle, Switzerland, for giving us the placebo. We also thank Mr E Law for doing the radioimmunoassays and Miss L Chan, Miss F Wong, and Miss $M$ Wong for their nursing care.

\section{References}

1 Nicholls $K$, Fairley $K$, Dowling J, Kincaid-Smith P. The clinical course of mesangial IgA associated nephropathy in adults. Qf Med 1984;53:227-50.

2 d'Amico G, Imbasciati E, di Belgioiosco G, et al. Idiopathic IgA mesangial nephropathy. Medicin 1985;64:49-60.

3 Clarkson AR, Seymour AE, Chan YL, Thompson AJ, Woodroffe AJ. Clinical, pathological and therapeutic aspects of IgA nephropathy. In: Kincaid-Smith P, d'Apice A, Atkins R, eds. Progress in glomerulonephritis. New York: John Wiley and Sons, 1979:247-58.

4 Egido J, Rivera F, Sancho J, Barat A, Hernando L. Phenytoin in IgA nephropathy: a long-term controlled trial. Nephron 1984;38:30-9.

5 Lai KN, Lai FM, Ho CP, Chan KW. Corticosteroid therapy in IgA nephropathy with nephrotic syndrome: a long-term controlled trial. Clin Nephrol 1986;26:174-80.

6 Hess AD, Tutschka PJ, Pu Z, Santos GW. Effect of cyclosporin A on human lymphocyte responses in vitro. IV. Production of $T$ cell stimulatory growth factors and development of responsiveness to these growth factors in CyA-treated primary MLR cultures. F Immunol 1982;1:360-7.

7 Cattran DC, Dossetor J, Halloran PF, et al. Cyclosporin in glomerulonephritis-a pilot study. In: Schindler $\mathbf{R}$, ed. Cyclosporin in autoimmune disease. Heidelberg: Springer Verlag, 1985. $311-5$.

8 Tipping PG, Holdsworth SR. Effect of cyclosporin A on antibody-induced experimental glomerulonephritis. Nephron 1985;40:201-5.

9 Gunn HC, Ryffel B. Glomerulonephritis in NZB/W mice: therapeutic effect of cyclosporine. Clin Nephrol 1986;25:S189-92.

10 Lai KN, Lai FM, Chan KW, Ho CP, Leung A, Vallance-Owen J. An overlapping syndrome of IgA nephropathy and lipoid nephrosis. Am f Clin Pathol 1986;86:716-23.

11 Lai KN, Ho CP, Chan KW, Yan KW, Lai FM, Vallance-Owen J. Nephrotic range proteinuriaa good predictive index of disease in IgA nephropathy? $Q \mathcal{O F}$ Med 1985;57:677-88.

12 Hale GM, McIntosh S, Hiki Y, Clarkson AR, Woodroffe AJ. Evidence for IgA-specific B cell hyperactivity in patients with IgA nephropathy. Kidney Int 1986;29:718-24.

13 Egido J, Blasco R, Sancho J, Lozano L. T-cell dysfunction in IgA nephropathy: specific abnormalites in the regulation of IgA synthesis. Clin Imomol Immenopathol 1983;26:201-12.

14 Meyrier A, Simon P, Perret G, Condamin-Meyrier M. Remission of idiopathic nephrotic syndrome after treatment with cyclosporin A. Br Med J 1986;292:789-92.

15 van Rijthoven A, Dijkmans B, Goei HT, et al. Cyclosporin treatment for rheumatoid arthritis: a placebo controlled, double blind, multicentre study. Ann R heum Dis 1986;45:726-31.

16 Palestine AG, Austin III HA, Nussenblatt RB. Renal tubular function in cyclosporin-treated patients. Am J Med 1986;81:419-24.

(Accepted 9 September 1987) 